\title{
Lo que se perdió: crónica del presente
}

\author{
Gone Away: Chronicle of the Present
}

\section{VÍCTOR FOWLER CALZADA}

Poeta, ensayista, crítico, narrador. Ha publicado los poemarios El próximo que venga, Estudios de cerámica griega, Confesionario, Descensional, Visitas, Malecón Tao, Caminos de piedra, Historias del cuerpo y El maquinista de Auschwitz. Es también autor de tres novelas y cientos de cuentos aún inéditos, así como de los ensayos La maldición, una historia del placer como conquista y Rupturas y homenajes, y de la antología La eterna danza, contentiva de la poesía erótica cubana de los últimos doscientos años.

ENSAYO. Este texto publicado en 2003 tiene una cierta dimensión fundacional en el ámbito de estudio de las relaciones cubano-rusas postsoviéticas. Está considerado como uno de los primeros artículos que plantearon abiertamente una cierta nostalgia y la idea de la pérdida como un sentimiento contradictorio y paradójico. Fue publicado originalmente en la revista Dédalo 0 (2003):12-13. Lo reproducimos aquí gracias al consentimiento de su autor.

RECIBIDO: 3 DE MARZO DE 2015

ACEPTADO: 8 DE MARZO DE 2015

DOI: 10.7203/KAM.5.5011 
Víctor Fowler. Lo que se perdió...

Supongo que haya sido en el 91 ó 92, en todo caso hace casi diez años, cuando en el entonces casi inexistente Tent Cent de la calle Galiano contemplé esta escena sobre una de las improvisadas tarimas se ofertaban fotografías del actor soviético Maxim Isáiev. El resto del espacio era ocupado por gomas, lápices, libretas, presillas, plumas, almanaques de pared o de bolsillo, hebillas de pelo y mil otros objetos útiles para la vida cotidiana, de modo que las fotos resaltaban como algo extraño que no debía estar. Observando desde hoy, la escena destaca por lo incongruente y hasta nos preguntamos cómo llegaron esas fotos, más propias de un puesto de periódicos, a un sitio donde se buscan herramientas, utensilios domésticos o cosas de oficina. Claro que desde hoy sé que son un sobrante o residuo, gránulos de algo que no hay dónde colocar y a lo que tampoco se ha querido echar al cesto: en cierto sentido una manifestación de nostalgia (en el funcionario que decidió ponerlas a la venta), quizás hasta una demostración de fe, puesto que aun confiaba en que habría compradores para su material. Cualquier matemática enseña que estoy hablando de los años en los que el poderoso sistema socialista recién acababa de desintegrarse ante los ojos azorados de media humanidad: nosotros, los cubanos, entre ella. Eso permite profundizar en la extrañeza de esa imagen de un actor encima de una mesa pobre, llena de objetos para la supervivencia. En especial porque ningún otro colega de profesión, extranjero o cubano, lo acompañaba: en cuanto al presente, el cultivo de un sistema de estrellas es una zona de la industria cultural que apenas hoy comienza a desarrollarse en nuestro país. Insisto en que se trata de un residuo, como los que llenan las aguas después de los naufragios.

A los de mi época, y mayores, les será difícil olvidar al actor que encarnó a Stirlitz en 17 instantes de una primavera, adaptación a la pantalla televisiva de una conocida novela de Iulián Semiónov, pero ¿quién es, para los que andan entre los 15-30 años, Maxim Isáiev? Nada, un rostro mudo, un tramo vacío que a nosotros, que a quienes pudimos disfrutar su arte, nos habla de lo que se perdió; un síntoma, pues el hecho de que esas fotos de repente aparezcan, en cantidad suficiente para aún ser vendidas, quizás indique un periodo donde debieron existir, en almacenes de todo tipo, miles de ellas. Su descolocación encima de aquella mesa nos habla también de un aparato cultural puesto al servicio de su difusión: dicho de otro modo, hubo una época en la que su lugar era otro, en la que había la coherencia necesaria a un mercado, entre los productores y los vendedores del material, entre la mercancía y su público.

Uno de los misterios que desafía a expertos de variadas áreas, y que ojalá sea tratado por investigadores cubanos antes que por cubanólogos, es la velocidad con la que han desaparecido de la sociedad cubana los signos, no pocas veces agobiantes, de los países del antiguo bloque socialista. El mundo empresarial se desprende de una tecnología, muchas veces atrasada desde su misma introducción al país, al tiempo que los que todavía dependen de las hazañas de durabilidad de los camiones Zil, jeeps, tractores, motoniveladoras, etcétera, rezan para que no tarden los fondos que posibiliten renovar viejos 
Víctor Fowler. Lo que se perdió...

parques. El mundo militar está fuertemente atado a ese pasado: lo principal del armamento, las técnicas de combate y una gran nostalgia; pero incluso aquí, al desaparecer el escudo bélico que fueron aquellos países, las doctrinas combativas debieron transformarse. Para el ciudadano común, más allá de las casas en las que sobreviven televisores Electrón o algún radio Selena, de los miles que llevan nombres de ajena tradición (Anatoli, Lenin, Igor, etcétera), de la pasión por el té negro y los recuerdos, es dudoso que haya mucho más.

Se me dirá que exagero, que los miles de cubanos que fueron a estudiar a aquellos países o que vieron sus vidas ligarse estrechamente a ellos, en un amplio abanico que iba desde las necesidades de trabajo hasta el matrimonio, no es posible que hayan olvidado; pero ocurre que más bien hablo de sustituciones y reacomodos de la subjetividad abierta a nuevas circunstancias. A esta cantidad humana de personas, que habitamos todos el tejido del universo del antiguo socialismo, habría que agregar las decenas de miles para quienes esto nuevo que vivimos hoy ha sido la única circunstancia que pueden razonar; ha transcurrido más de una década desde la desaparición de aquello, desde la atenuación de toda referencia a lo allí sucedido hasta llegar al vacío de hoy. Dicho de otro modo, unos cambiamos las coordenadas socio-culturales con las cuales operamos, otros ni siquiera tienen algo para cambiar: simplemente nacieron aquí. La velocidad e importancia de los cambios sociales que hemos vivido en diez años son tales, y tanta la diferencia con lo anterior, que parecieran, paradójicamente, haber tenido lugar hace mucho; extraño espejismo que lo mismo se instala en los nuevos significados y palabras que trastornan el lenguaje, que en el cambio de lealtades culturales visible en las referencias de la prensa, la música difundida, la programación televisiva, los libros publicados, la comida que se consume, la ropa que se viste y, en general, los panteones heroicos o el sistema de ídolos y expectativas de vida.

Un periódico de hace 15, 20 años, remite a un mundo que se aproxima a un relato maravilloso. Eso que hoy damos como algo perdido estaba en todas partes: televisión, radio, cine, libros, encuentros deportivos, simples noticias. Es rara la pérdida de tanto, como si el inmenso esfuerzo de influencia cultural que recibimos no hubiese generado más que una inmensa superficie bajo la cual, lo ajeno a la tradición nunca dejó de serlo. Los chistes del payaso Ferdinando eran de complicada intelección para los niños y no recuerdo alguno que se riese, aunque en verdad tampoco los que se aburriesen de verlo. Las hazañas de los Cuatro tanquistas y un perro resultaban menos atractivas que una telenovela brasileña de hoy, además de que padecían un espantoso doblaje: apenas conseguí llegar al primer tomo cuando las publicó esa extrañada (¡ay!) Colección Huracán. Karel Gott nos parecía un aburridísimo Rafael (el español) cantando en checo; Bisser Kirov un tipo con cara siempre de divertido; Muslim Magomáev un bolerista de segunda línea; Ala Pugachova era buena, pero no mejor que Aretha Franklin y tampoco entendíamos bien los motivos de su fama de artista problemática; muchos que regresaban traían su culto 
Víctor Fowler. Lo que se perdió...

privado a Vladimir Vosotski, pero no comprendíamos su lugar por no saber el idioma. Había buenos grupos de rock, No To Co (Polonia), Boris Grebenshikov con su banda Aquarium (URSS), Katy Kóvacs y, sobre todo, Locomotiv, de Hungría, pero ni en sueños se aproximaban a The Beatles, Led Zeppelin, Deep Purple, Rolling Stones o Emerson, Lake and Palmer. Señalo el listado porque, no en vano, muchos de los que estudiaban en aquellos países retornaban cargados de discos de estos grupos; como por casualidad, los mismos que los medios cubanos se esforzaban por ni siquiera mencionar. A cambio de ello, ya lo hemos visto, nos llegaban sustitutos. ¡Cuántos espejismos! Ein Kessel Buntel, aquellos radiotocadiscos marca Sinfonía que hoy lucen como inmensos escaparates, patéticos en su ansia de reproducir los signos exteriores de un supuesto confort burgués. Los buenos, pero inatractivos relojes de la marca Poljot, los pequeñísimos y fuertes radios Órbita, las grabadoras, inmensas como maletas, que traían los viajeros. Todo esto, y mucho más, es cierto pero, en su reverso, tratábamos de leer el Doctor Zhivago, Nosotros y El maestro y Margarita (el último sólo en edición española, por entonces); aprovechábamos la magnifica capacidad de sintonización de los radios Selena para escuchar verdadero rock en las emisoras norteamericanas de FM; y perseguíamos los poemas de Evtushenko, Ajmátova, Pasternak. Pese a todo lo que allí había de ridículo e impuesto, escribo para lamentar un mundo desaparecido: esa "quinta parte de la humanidad" que la propaganda proponía desbordante y que ahora recuerdo con tristeza. Porque aquél era, también, el lugar de Aitmátov y Tibor Déry, del cartel polaco, de cinematografías en las que había películas excelentes, concertistas de música culta y cantantes de ópera de primera calidad, compañías de ballet clásico célebres, deportistas gloriosos, pensadores agudos, actores de primera calidad, gente, en fin, vida. ¿Qué se ha hecho de todo esto, qué ha venido después?

Uno de los errores lamentables de nuestra política cultural reciente ha sido, a mi entender, el haberse resignado a la sustracción de la producción cultural de los países del antiguo bloque socialista; apenas se escucha noticia sobre algún acto creativo que de allí provenga, como si la totalidad de la vida hubiese desaparecido luego de los derrumbes del sistema político amigo que allí regía. Tal vez las susceptibilidades políticas justifiquen semejante actitud, más no la inteligencia mínima necesaria para las decisiones culturales ya que, justamente, por motivos políticos, es que sería necesario conocer lo que ahora, justo ahora, pueda estar sucediendo en tales zonas. Me refiero a que, incluso desde las coordenadas del socialismo cubano, resulta imprescindible saber cuáles han sido las respuestas, tanto artístico-literarias como a nivel teórico y de pensamiento, que han surgido ante las nuevas realidades (la dura construcción del capitalismo contemporáneo) que hoy enfrentan dichos países. ¿Quiénes son los escritores del presente, los cineastas, los filósofos, los sociólogos, los analistas políticos, los culturólogos? ¿Cómo es posible que tan inmensa riqueza sea echada a un lado por nuestros funcionarios políticos, ideólogos o dirigentes culturales? Claro que ahora no hay un sistema de relaciones y convenios 
que facilite el contacto, que muchas de las antiguas estructuras de producción y difusión se hundieron; pero un país, lo sabemos por el nuestro, es un tejido delicado y tan grande como la totalidad de sus ciudadanos; lleno de contradicciones, de puntos de dolor, de desarrollo, donde al acomodamiento del comercialismo se opone el deseo de vivir una vida auténtica, donde hay belleza incluso en la pudrición. La cultura es una totalidad y ahora que las lealtades ideológicas y las conexiones burocráticoadministrativas con aquel mundo desaparecieron, quizás sea el momento de regresar a la producción cultural y espiritual; sin obligaciones ni normativas, sino con la libertad y la alegría necesarias para el encuentro con la verdad. Deberíamos hacerlo. 